\title{
City Lockdown and Nationwide Intensive Community Screening Are Effective In Controlling COVID-19 Epidemic: Analysis Based on A Modified SIR Model
}

\section{Tailai Peng}

Department of Anesthesiology and Translational Neuroscience Center, West China Hospital, Sichuan University and University of Chinese Academy of Sciences

\section{Xinhao Liu}

Department of Anesthesiology and Translational Neuroscience Center, West China Hospital, Sichuan University

\section{Hefeng Ni}

University of Chinese Academy of Sciences

\section{Zhe Cui}

University of Chinese Academy of Sciences

Lei Du ( $\nabla$ dulei@scu.edu.cn )

Department of Anesthesiology and Translational Neuroscience Center, West China Hospital, Sichuan University

\section{Research Article}

Keywords: COVID-19, Modified SIR model, City lockdown, Intensive community screening, China experience

Posted Date: April 8th, 2020

DOl: https://doi.org/10.21203/rs.3.rs-22056/v1

License: (c) (1) This work is licensed under a Creative Commons Attribution 4.0 International License. Read Full License

Version of Record: A version of this preprint was published at PLOS ONE on August 28th, 2020. See the published version at https://doi.org/10.1371/journal.pone.0238411. 
City Lockdown and Nationwide Intensive Community Screening Are Effective In Controlling COVID-19 Epidemic: Analysis Based on A Modified SIR Model

Tailai Peng ${ }^{1,2+}$, MS, Xinhao Liu ${ }^{1+}$, M.D., Hefeng Ni² ${ }^{2}$ B.S, Zhe Cui ${ }^{2}$,Ph.D., Lei Du ${ }^{1 *}$, M.D.

${ }^{1}$ Department of Anesthesiology and Translational Neuroscience Center, West China Hospital, Sichuan University, Chengdu, Sichuan, China.

${ }^{2}$ University of Chinese Academy of Sciences, Beijing, China.

†These authors contributed equally to this work

*Correspondence: Dr Lei Du, Department of Anesthesiology and Translational Neuroscience Center, West China Hospital, Sichuan University, No. 37, Guoxue Alley, Chengdu, Sichuan, 610041, P.R. China. E-mail: dulei@scu.edu.cn. Tel: +8618980601926. 


\begin{abstract}
:
In December 2019, an outbreak of COVID-19 epidemic occurred in Wuhan, China and this infection has spread rapidly into more than 109 countries around the world. To limit the rapid spread in community and nationwide, Wuhan city lockdown and nationwide intensive community screening were employed by Chinese government. To assess the effectiveness of city lockdown and intensive community screening, we built a modified SIR model by introducing an $\alpha$ value into the classic SIR model. The $\alpha$ value represents the proportion of the infected that is not effectively isolated from the susceptible at a given time point. The $\alpha$ value of China excluding Hubei province was largely reduced by Wuhan city lockdown. Although the $\alpha$ value of Wuhan city dropped a little with city lockdown, but dropped rapidly with intensive community screening. With the decrease of $\alpha$ value, the epidemic in China would be end at the beginning of June 2020. With current epidemiological data, the infection cases in South Korea and Italy are predicted to increase exponentially in the next days, if stringent mitigation measures were not adopted.
\end{abstract}

Key word : COVID-19; Modified SIR model; City lockdown; Intensive community screening; China experience 


\section{Background}

An outbreak of novel coronavirus (SARS-CoV-2) infection occurred in Wuhan city, China in December 2019(1). The World Health Organization (WHO) has declared the disease caused by SARS-CoV-2 infection as coronavirus disease 2019 (COVID-19). The cumulative number of people with COVID-19 has surged over 80,000 in China and 140,000 worldwide in more than 109 countries around the world, and the official reported death toll exceeds 5300 (2-4). Although cross-species transmission of SARS-CoV-2 has not been clarified, the rapid person to person transmission was linked to the seafood market (Huanan Seafood Wholesale Market)(5). The timing of the outbreak is right before the traditional Chinese New Year when mass migration occurs every year, which facilitates the spread of the epidemic. What makes the situation worse is that Wuhan is one of the largest cities in China with 11 million population and have highly mobile transportation system, including flight, express train and local bus. So far there is no specific medication for SARS-CoV-2 infection but supportive care(6). To halt this serious public health event, Chinese government implemented two stringent mitigation measures, Wuhan city lockdown and nationwide intensive community screening.

In this study, with current epidemiological data, we measured the effectiveness of these two measures through a modified SIR model. We validated the accuracy of the model with real world data of Guangdong province and Zhejiang province of China and predicted the end of epidemic in China. We also predict the trend of epidemic in seriously infected countries, such as Italy and South Korea with this model.

\section{Methods}

\section{Data source}

The reported cases of COVID-19 were collected from $8^{\text {th }}$ December 2019 to $12^{\text {th }}$ March 2020 by Tencent real time tracking(7), Ifeng real time tracking(8) and data from National Health Commission of the People's Republic of China(9). Our data includes new infections, new cures, new deaths, cumulative diagnoses, cumulative discharges, and cumulative deaths each day. Because our data is in unit of 'days', our model will also iterate in unit of 'days' to produce daily result. 


\section{Establishing SIR model}

The present study used the classic SIR model to build a mathematical model, where S represents the susceptible, I represents the infected, and R represents recovered.

Suppose $i(t), s(t)$ and $r(t)$ represent the numbers of the infected, the uninfected and the recovered individuals respectively at time $t$. Meanwhile, $\beta$ (effective daily infection rate) is defined as $\lambda \times p$, where $\lambda$ is the number of both infected and healthy individuals' effectively contacts with per infected individual per day, and $p$ is the infection probability of the effective contact. The model equations are established as follows:

$$
\begin{gathered}
i(t+\Delta t)-i(t)=i(t) \times \beta \times \frac{s(t)}{N} \times \Delta t-i(t) \times \mu \times \Delta t \\
s(t+\Delta t)-s(t)=-i(t) \times \beta \times \frac{s(t)}{N} \times \Delta t \\
r(t+\Delta t)-r(t)=i(t) \times \mu \times \Delta t
\end{gathered}
$$

$\frac{s(t)}{N}$ represents the proportion of healthy individuals in the effective contacts, because the disease can only be transmitted by contacting them.

\section{Calculation of " $p$ ” (Infection probability)}

We calculated the $p$ using data from the first available local data of Wuhan city (January $18^{\text {th }}$ 2019 ) to the implement of city lockdown (January $23^{\text {th }} 2019$ ). Infection number was calculated by the cumulative confirmed cases minus cumulative hospital discharges and deaths. Based on the initial $i(t)$, and the real time $i(t)$ during this period, the value of $p$ in $i(t)$ was found. Since the initial $N \approx s(t)$, we can simplify (1) to get:

$$
\frac{d i}{d t}=(\beta-\mu) \times i(t)
$$

According to (4), the expression $i(t)$ can be obtained:

$$
i(t)=C \times e^{(\beta-\mu) t}
$$

Due to $i(0)=1$, get $C=1$, then:

$$
i(t)=e^{(\beta-\mu) t}
$$


Taking $\beta=\lambda \times p$ into (6), we get:

$$
i(t)=e^{(\lambda p-\mu) t}
$$

We assumed the number of effective daily contacts per infected person is 5 , (ie, $\lambda=5$ ), and according to Chinese statistics, the average length of hospitalization in Wuhan city is currently 20 days, and non-Hubei area is 9 days, so the average length of hospitalization is $\left\lfloor\frac{20+9}{2}\right\rfloor=14$ days , so $\mu=1 / 14$ is taken. Because the first case was found on December 8 , the value of " $t$ " is the difference between a given date and December 82019 .

Then the fitted objective function is:

$$
\min \sum_{t \in T}\left(e^{(\beta-\mu) t}-I(t)\right)^{2}
$$

$I(t)$ is the number of patients on $t$ days after December 8 .

Based on the data of Wuhan from $18^{\text {th }}$ December 2019 to $22^{\text {th }}$ December 2019, we got: $p=0.040$, $\mathrm{R} 0=2.805$

\section{Establishing Modified SIR Modeling}

Two conditions should be taken into consideration during establishment of SIR model. First, the isolated infected individuals were no longer able to transmit to others but have chance to recovery with the implement of mitigation measures. Second, some virus-carrier would transmit to others without limitation. The 2 conditions would induce $\lambda$ changes, which means the effective contact of per infected individuals with the healthy individuals per day would be changed. In order to adapt the changes, we introduced an $\alpha$ value to the classic SIR model. The $\alpha$ was 1 at the beginning of epidemic, which means not limitation of spread of epidemic disease. Then the value would be reduced after the implement of mitigation measures. The lower $\alpha$ value means the effective isolation of the infected individuals.

After $\alpha$ was introduced into formulas (1), (2), (3), we got formulas (8), (9), (10) as follows:

$$
i(t+\Delta t)-i(t)=i(t) \times \alpha \times \lambda \times p \times \frac{s(t)}{s(t)+i(t) \times \alpha} \times \Delta t-i(t) \times(1-\alpha) \times \mu \times \Delta t
$$




$$
\begin{gathered}
s(t+\Delta t)-s(t)=-i(t) \times \alpha \times \lambda \times p \times \frac{s(t)}{s(t)+i(t) \times \alpha} \times \Delta t \\
r(t+\Delta t)-r(t)=i(t) \times(1-\alpha) \times \mu \times \Delta t
\end{gathered}
$$

We used formula (10) to calculate the daily $\alpha$ value, where $r(t+\Delta t)-r(t)$ is the number of newly discharged patients on that day, and $i(t)$ is the total number of existing patients on that day. To measure the $\alpha$ trend, we first calculate the true $\alpha$ value of the target day as $\alpha_{t}$, then we calculate the $\alpha$ value of the day before the target day as $\alpha_{b}$. Then we take $\alpha=$ $\left(\alpha_{b}+\alpha_{t}\right) / 2$ as the target day's $\alpha$. Experiments have shown that this can increase the accuracy of the fit.

To calculate the daily $\lambda$ value, the calculated $\alpha$ value above is taken into equation (8), where $i(t+\Delta t)-i(t)$ is the number of newly diagnosed patients on that day, and $i(t)$ is the existing number of patients on that day. $s(t)$ is the difference between the total population $(\mathrm{N})$ and the cumulative number of patients on the day.

\section{Prediction of new $\alpha$ values}

The prediction of cumulative cases needs the $\alpha$ value of each day. Supposing to predict the $\alpha$ value for $\mathrm{M}$ days starting from day T, we selected the real $\alpha$ values for $\mathrm{n}$ days (T-n, T-1) and fitted its trend. Usually $\mathrm{n}$ between 10 and 15 was required and the latest trend of $\alpha$ value in the $\mathrm{n}$ days was used to fit the function. The fitting method for $\alpha$ is as follows. First, if the available data is less than 5 days and the maximum difference between the values is less than 0.1 , then the alpha value is averaged. Second, if the available data is more than 5 days, both First-order linear regression and second-order linear regression were used to fit, respectively. Then we select the appropriate regression equation as the prediction function based on prior knowledge and fitting errors.

\section{Predicting the infection cases with the predicted $\alpha$ value}

Based on the predicted $\alpha$ values above, we built a model according to (8), (9), (10). We substituted current last day's $i(t), s(t), r(t)$ into these formulas, and brought in the predicted $\alpha$ one by one. Each time we brought in an $\alpha$ value, and got next day's $i(t), s(t), r(t)$. After repetition for $n \alpha$ values, the infection cases $(i(t))$ for the next $n$ days would be predicted. 


\section{Results}
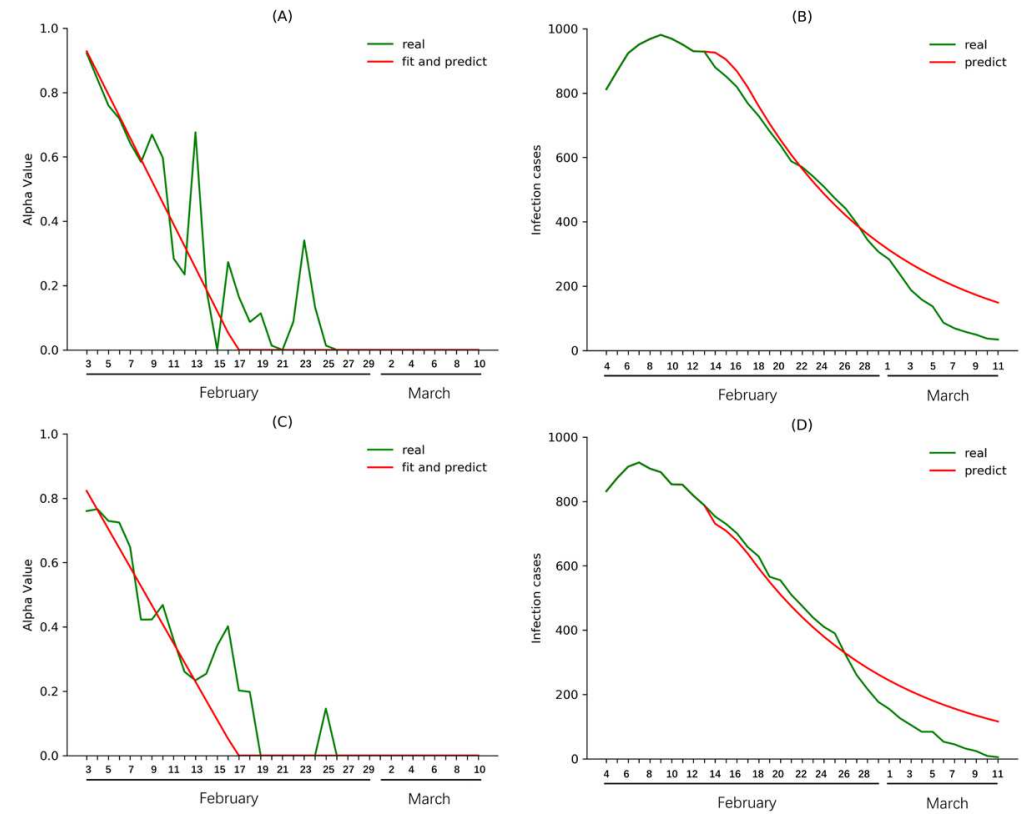

Figure 1 Validation of modified SIR model with data of Guangdong and Zhejiang Province. The $\alpha$ values from February $3^{\text {rd }}$ to February $12^{\text {th }}$ (before nationwide intensive community screening but after Wuhan city lockdown) were used to predict $\alpha$ values from February $13^{\text {th }}$ to March $10^{\text {th }}$ for Guangdong (A) and Zhejiang (C). Predicted $\alpha$ values from February $13^{\text {th }}$ to March $10^{\text {th }}$ were used to predict the $\mathrm{i}(\mathrm{t})$ from February $14^{\text {th }}$ to March $11^{\text {th }}$ for Guangdong (B) and Zhejiang (D).

\section{Validation of Modified SIR Model}

We made predictions for Guangdong and Zhejiang province to verify the accuracy of the model. Data of Guangdong and Zhejiang from February $3^{\text {rd }}$ to February $12^{\text {th }}$ were used to fit the trend of $\alpha$ values. Then the fitted trend was used to predict the $\alpha$ value from February $13^{\text {th }}$ to March $10^{\text {th }}$. The predicted $\alpha$ values were taken into the modified SIR model along with the $i(t), s(t), r(t)$ of February $13^{\text {th }}$ to predict the $i(t), s(t), r(t)$ on each day. As shown in Figure 1, the predicted $\alpha$ values and infection cases of Guangdong and Zhejiang province were well in accordance with the real numbers before March 1, and they decreased sharply after the implement of Wuhan city lockdown. This result reflected the accuracy of this model. However, the predicted cases are higher than the real infection cases in Guangdong (148 vs. 34) and Zhejiang (116 vs. 5) on March $11^{\text {th }}$, which may be due to the delayed effect of nationwide intensive community 
screening (beginning on February $16^{\text {th }}$ and the cases decreased from February $27^{\text {th }}$, delayed about 10 days) to further reduce the $\alpha$ value.
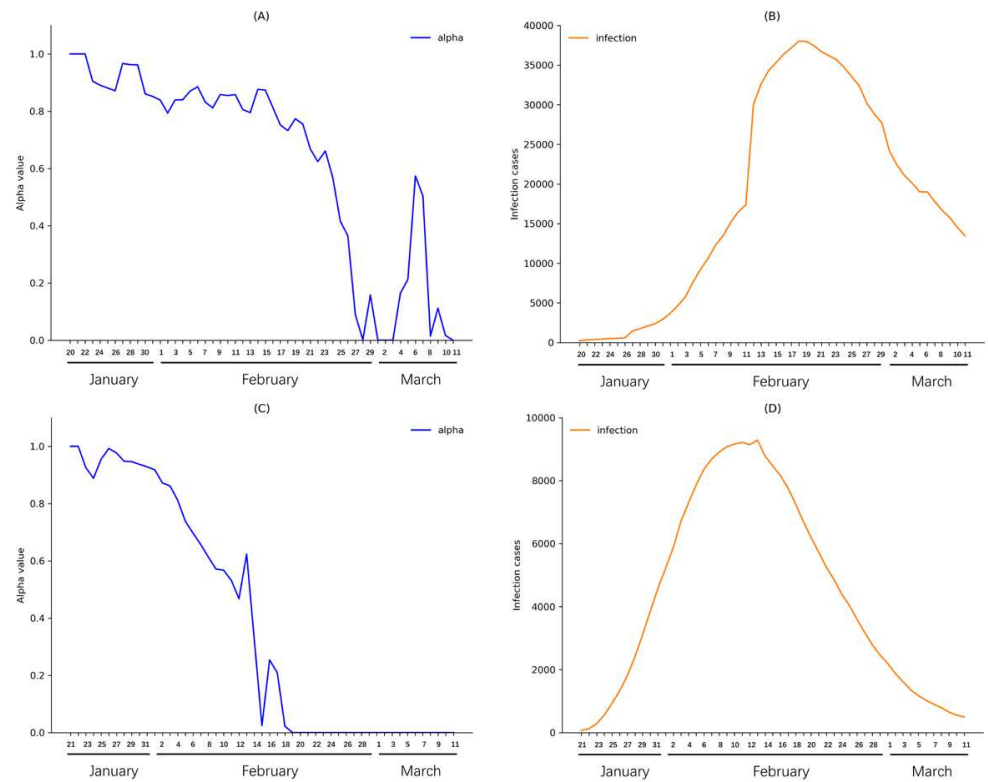

Figure 2. Real world $\alpha$ value and infection cases of Wuhan city from January $20^{\text {th }}$ to March $11^{\text {th }}$ and China excluding Hubei from January $21^{\text {th }}$ to March $11^{\text {th }}$. Real $\alpha$ value (A) and infection cases (B) of Wuhan city; Real $\alpha$ value (C) and infection cases (D) of China excluding Hubei.
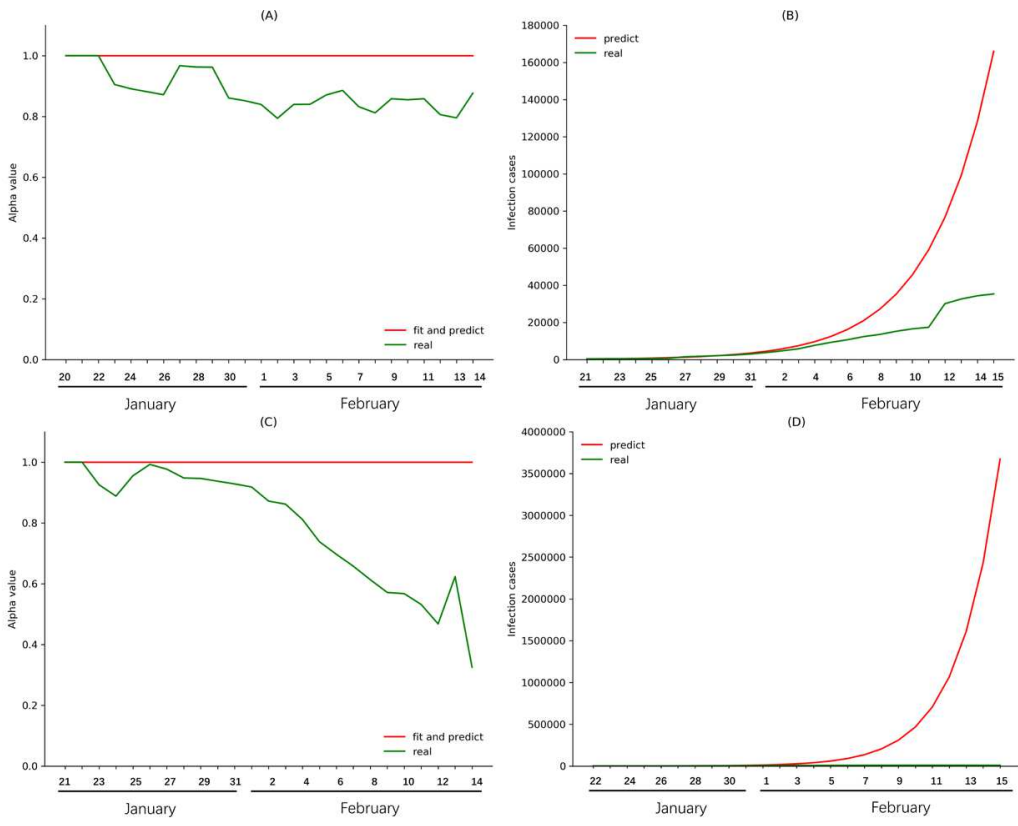

Figure 3. Impact of city lockdown on Wuhan city and China excluding Hubei province. (A) $\alpha$ values of Wuhan city from January $20^{\text {th }}$ to January $22^{\text {th }}$ (before city lockdown) were used to predict the $\alpha$ value from January $23^{\text {th }}$ to February $14^{\text {th }}$ without city lockdown. (B) Predicted $\alpha$ values were used to calculate the infection number of Wuhan city from January $24^{\text {th }}$ to February $15^{\text {th }}$. (C) $\alpha$ values of China excluding Hubei province from January $21^{\text {th }}$ to January $22^{\text {th }}$ were used to predict the $\alpha$ value from January $23^{\text {th }}$ to February $14^{\text {th }}$ without city lockdown. (D) Predicted $\alpha$ values were used to 
calculate the infection cases of China excluding Hubei province from January $24^{\text {th }}$ to February $15^{\text {th }}$.
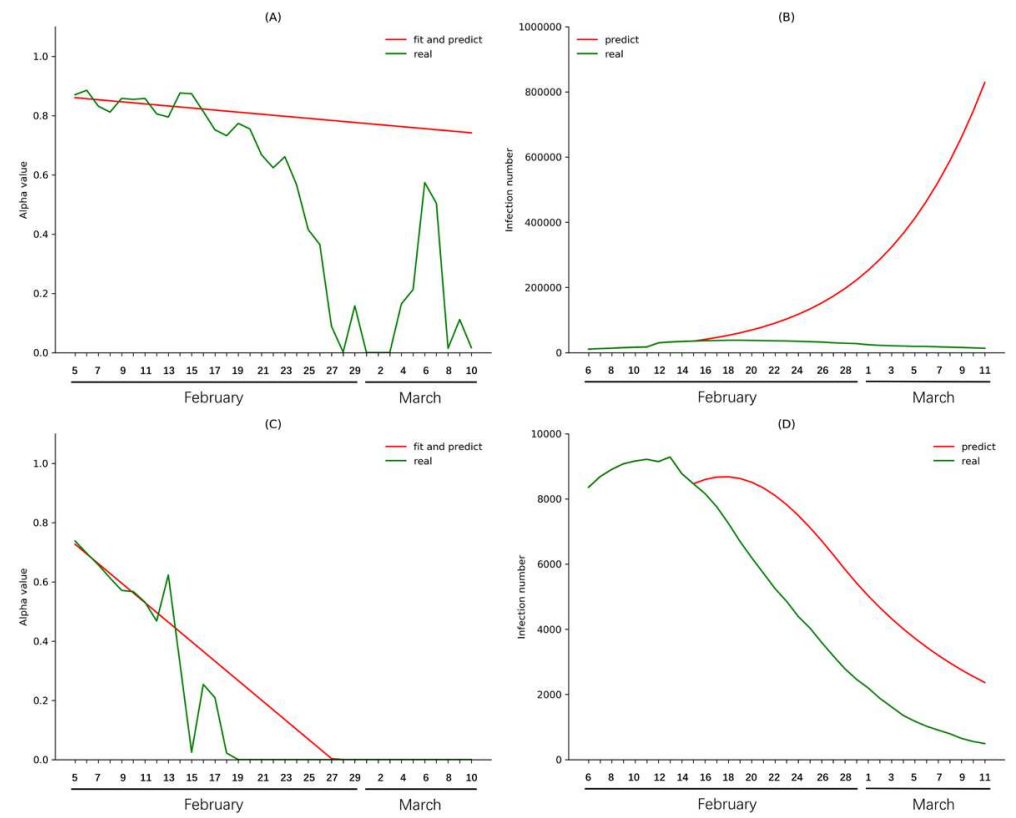

Figure 4. Impact of intensive community screening on Wuhan city and China excluding Hubei province (A) $\alpha$ value from February $5^{\text {th }}$ to February $14^{\text {th }}$ (before intensive community screening) were fitted to predict the $\alpha$ value of Wuhan city from February $15^{\text {th }}$ to March $10^{\text {th }}$ without intensive community screening. (B) predicted $\alpha$ values were used to calculate the infection cases of Wuhan city from February $16^{\text {th }}$ to March $11^{\text {th }}$. (C) $\alpha$ value of China excluding Hubei Province from February $5^{\text {th }}$ to February $14^{\text {th }}$ were used to predict the $\alpha$ value of China excluding Hubei Province from February $15^{\text {th }}$ to March $10^{\text {th }}$ without intensive community screening. (D) predicted $\alpha$ values were used to calculate the infection number of China excluding Hubei Province from February $16^{\text {th }}$ to March $11^{\text {th }}$.

\section{Evaluation of the effectiveness of city lockdown and intensive community screening}

We calculated $\alpha$ values of Wuhan city and China excluding Hubei (Figure 2), and found that the $\quad \alpha$ value of Wuhan decreased slightly after city lockdown (from 0.905 on January $23^{\text {th }}$ to 0.814 on February $\left.16^{\text {th }}\right)$. However, the $\alpha$ value of China excluding Hubei decreased steadily after January $23^{\text {th }}$ (from 0.926 on January $23^{\text {th }}$ to 0.254 on February $16^{\text {th }}$ ). The result suggested that the rapid spread of the virus from Wuhan to other cities had been effectively suppressed, but the local spread in Wuhan was not.

The nationwide intensive community screening (on February $16^{\text {th }}$ ), was associated with significantly decrease of $\alpha$ value of Wuhan city (from 0.814 on February $16^{\text {th }}$ to 0 on March $11^{\text {th }}$ ) and China excluding Hubei (from 0.254 on February 16 to 0 on March $11^{\text {th }}$ ), suggested that the contact between the infected and the susceptible was greatly reduced nation widely. As a result, the infected cases decreased significantly from 36385 and 8163 on February 16 to 13462 and 493 
on March $11^{\text {th }}$, respectively, in Wuhan and China excluding Hubei (Figure 2).

Next, we predicted the increase of infection cases, supposing the 2 measures had never been implemented. To assess the impacts of city lockdown on Wuhan, data of Wuhan city from January $20^{\text {th }}$ to January $22^{\text {th }}$ were used to predict the $\alpha$ value from January $23^{\text {rd }}$ to February $14^{\text {th }}$, and the infection cases of Wuhan from January $24^{\text {th }}$ to February $15^{\text {th }}$ was predicted with simulated $\alpha$ values. Similar analyses were performed with data of China excluding Hubei. The infection cases of Wuhan city and China excluding Hubei would be 165,923 , and 3,673,386, respectively, on February $15^{\text {th }}$. In fact, with city lockdown, the real infection cases of Wuhan city and China excluding Hubei were 35,314 and 8,463, respectively (Figure 3).

Similar analyses were performed to evaluate the effectiveness of intensive community screening. For Wuhan city and China excluding Hubei, the $\alpha$ values from February $15^{\text {th }}$ to March $10^{\text {th }}$ were predicted with data from February $5^{\text {th }}$ to February $14^{\text {th }}$ and then infection cases from February $16^{\text {th }}$ to March $11^{\text {th }}$ was predicted with the predicted $\alpha$ values. Infection cases of Wuhan city and China excluding Hubei were predicted to be 828,884 and 2,366 respectively on March $11^{\text {th }}$. In fact, with intensive community screening, the real infection cases of Wuhan city and China excluding Hubei were 13,462 and 493 respectively on March $11^{\text {th }}$ (Figure 4).
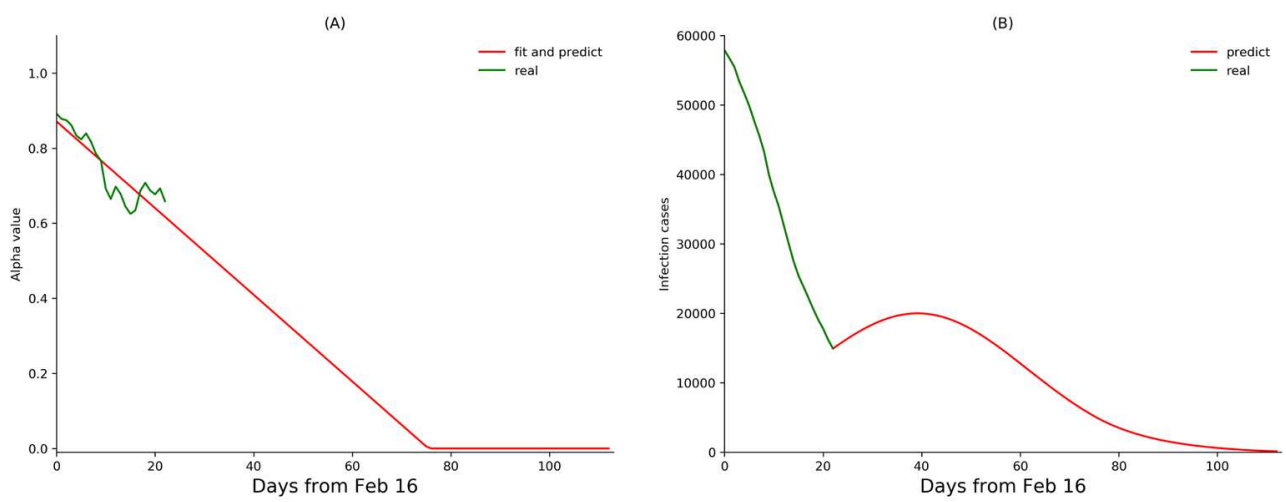

Figure 5. Prediction of the epidemic trend in China (A) $\alpha$ values from February $16^{\text {th }}$ to March $10^{\text {th }}$ were fitted to predict $\alpha$ values of 90 days from March $11^{\text {th }}$. (B) predicted $\alpha$ values were used to predict future infection cases $(i(t))$ in China. 


\section{Prediction of the trend of epidemic in China.}

The $\alpha$ values in next 90 days from March $11^{\text {th }}$ were obtained by fitting the $\alpha$ values from February $16^{\text {th }}$ to March $10^{\text {th }}$. Taking the initial $i(t), s(t), r(t)$ on March $10^{\text {th }}$, we predicted that the end time of epidemic in China is around the 90th day after March $11^{\text {th }}$, that is the beginning of the June (Figure 5).
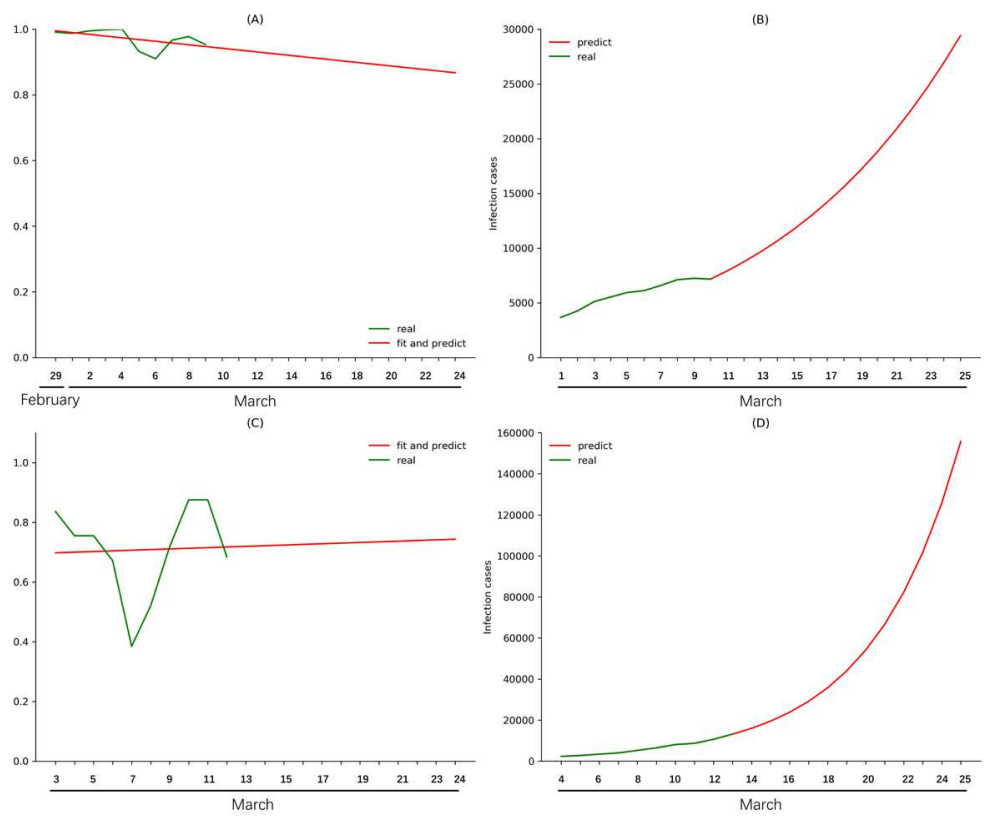

Figure 6. Prediction of the epidemic trend in South Korea and Italy. (A) $\alpha$ values from February $29^{\text {th }}$ to March $9^{\text {th }}$ were fitted to predict $\alpha$ values from March $10^{\text {th }}$ to March $24^{\text {th }}(\mathrm{B})$ predicted $\alpha$ values were used to calculate the infection cases from March $14^{\text {th }}$ to March $25^{\text {th }}$. (C) $\alpha$ values from March $3^{\text {th }}$ to March $12^{\text {th }}$ were fitted to predict $\alpha$ values from March $13^{\text {th }}$ to March $24^{\text {th }}$. (B) The predicted infection cases from March $14^{\text {th }}$ to March $25^{\text {th }}$.

\section{Prediction of the trend of epidemic in South Korea and Italy.}

For South Korea, the predicted $\alpha$ values from March $10^{\text {th }}$ to March $24^{\text {th }}$ were obtained by fitting the $\alpha$ values from February $29^{\text {th }}$ to March $9^{\text {th }}$. Taking the initial $i(t), s(t), r(t)$ on March $10^{\text {th }}$, we predicted the trend of epidemic in South Korea during this period, and the predicted infection cases would be 29400 on March $25^{\text {th }}$.

For Italy, $\alpha$ values from March $13^{\text {th }}$ to March $24^{\text {th }}$ were obtained by fitting the $\alpha$ values from March $3^{\text {th }}$ to March $12^{\text {th }}$. Taking the initial $i(t), s(t), r(t)$ on March $13^{\text {th }}$, we predicted the trend of epidemic in Italy from March $14^{\text {th }}$ to March $25^{\text {th }}$. The predicted infection cases of Italy 
would be 155,728 on March $25^{\text {th }}$ (Figure 6).

\section{Discussion}

Based on the classic SIR model in epidemic, R0 is calculated as 2.80 , which is similar to other studies $(1,10-14)$. However, this model could be not used to predict the development of epidemic when government was engaged to promote isolation of infected individuals and potential virus carriers. In this study, the $\alpha$ value was introduced in the SIR model, which represents the contact of the infected individuals and the susceptible person. The results showed that this modified-SIR model has highly accuracy in predicting infection cases, based on the data of Zhejiang and Guangzhou province.

Next the modified-SIR model was used to evaluate the effectiveness of city lockdown and intensive community screening. The predicted infection cases without those mitigation measures were much higher than the real infection cases in Wuhan and China excluding Hubei, suggesting that the two mitigation measures were effective in suppressing the spread of epidemic. A step-wise reduced $\alpha$ value may reflect the effective isolation of the infection cases. Specifically, Wuhan city lockdown largely decreased the $\alpha$ value of China excluding Hubei by containing the large proportion of infected individual in Wuhan city. On the other hand, intensive community screening significantly decreased $\alpha$ value of local Wuhan city. This is probably because hospital beds were extremely short in the beginning of the epidemic, which leads to a large proportion of infected individuals went back community and transmitted to family members and neighbors. Intensive community screening made the infected individuals or virus carriers to be isolated from healthy population by sending them to newly built medical center and quarantine facilities. With current mitigation measures along with more isolation facilities being built, it is anticipated that the epidemic in China would be end at the beginning of June.

According to current epidemiological data (15) and our prediction based on the modified SIR model, epidemic in South Korea and Italy would worsen, and the infection cases would increase exponentially in the next few days. Italy has ordered city lockdown in several city by suspending the public transportation, which may make the epidemic containing in the lockdown areas. Subsequent community screening is recommended next to limit the spreading inside the community, based on the experience from China. 
Our study has limitations. First, this modified SIR model predicts the $\alpha$ values based on current trend. If other disturbing events occur in the future, such as critical virus mutation and measures implemented by the government, the accuracy of the prediction will be impaired. Second, rapidly increase of discharge from hospital may change the real $\mu$ value, which may be adverse to the accuracy for prediction.

Despite these limitations, our results showed a reliable modified SIR model to predict the epidemic development. Based on this model, city lockdown is effective to block the spread from epidemic area to other cities, while intensive community screening may cut off the infected individuals to susceptible person. The 2 measures may help to control the now spreading epidemic, such as Italy, South Korea and other countries.

\section{Author Contributions}

Conceptualization, Lei Du; Data curation, Tailai Peng; Formal analysis, Tailai Peng and Xinhao Liu; Methodology, Hefeng Ni and Lei Du; Supervision, Zhe Cui; Writing - original draft, Xinhao Liu; Writing - review \& editing, Tailai Peng, Xinhao Liu, Hefeng Ni, Zhe Cui and Lei Du.

\section{Conflict of interest:}

All other authors declare no competing interests.

\section{Reference:}

1. Li Q, Guan X, Wu P, Wang X, Zhou L, Tong Y, et al. Early Transmission Dynamics in Wuhan, China, of Novel Coronavirus-Infected Pneumonia. The New England journal of medicine. 2020. 2. Organization WH. Coronavirus disease (COVID-2019) situation reports. 2020 3-14. Report No.: 54 .

3. Wang C, Horby PW, Hayden FG, Gao GF. A novel coronavirus outbreak of global health concern. Lancet. 2020;395(10223):470-3.

4. Holshue ML, DeBolt C, Lindquist S, Lofy KH, Wiesman J, Bruce H, et al. First Case of 2019 Novel Coronavirus in the United States. The New England journal of medicine. 2020;382(10):92936.

5. Zhu N, Zhang D, Wang W, Li X, Yang B, Song J, et al. A Novel Coronavirus from Patients with Pneumonia in China, 2019. The New England journal of medicine. 2020;382(8):727-33.

6. Murthy S, Gomersall CD, Fowler RA. Care for Critically III Patients With COVID-19. Jama. 2020. 7. Tencent. COVID-19 real time tracking 2020 [cited 2020 March 14]. Available from: https://news.qq.com/zt2020/page/feiyan.htm\#/global. 
8. Ifeng. COVID-19 real time tracking 2020 [cited 2020 March 14]. Available from: https://news.ifeng.com/c/specialClient/7tPIDSzDgVk?needpage=1\&webkit=1.

9. China NHCotPsRo. COVID-19 daily report 2020 [cited 2020 March 14]. Available from: http://www.nhc.gov.cn/xcs/yqfkdt/gzbd_index.shtml.

10. Zhang S, Diao M, Yu W, Pei L, Lin Z, Chen D. Estimation of the reproductive number of novel coronavirus (COVID-19) and the probable outbreak size on the Diamond Princess cruise ship: A data-driven analysis. International journal of infectious diseases : IJID : official publication of the International Society for Infectious Diseases. 2020;93:201-4.

11. Wu JT, Leung K, Leung GM. Nowcasting and forecasting the potential domestic and international spread of the 2019-nCoV outbreak originating in Wuhan, China: a modelling study. Lancet. 2020;395(10225):689-97.

12. Riou J, Althaus CL. Pattern of early human-to-human transmission of Wuhan 2019 novel coronavirus (2019-nCoV), December 2019 to January 2020. Euro surveillance : bulletin Europeen sur les maladies transmissibles = European communicable disease bulletin. 2020;25(4).

13. Tang B, Wang X, Li Q, Bragazzi NL, Tang S, Xiao Y, et al. Estimation of the Transmission Risk of the 2019-nCoV and Its Implication for Public Health Interventions. Journal of clinical medicine. 2020;9(2).

14. Zhao S, Musa SS, Lin Q, Ran J, Yang G, Wang W, et al. Estimating the Unreported Number of Novel Coronavirus (2019-nCoV) Cases in China in the First Half of January 2020: A Data-Driven Modelling Analysis of the Early Outbreak. Journal of clinical medicine. 2020;9(2).

15. Day M. Covid-19: surge in cases in Italy and South Korea makes pandemic look more likely. Bmj. 2020;368:m751. 

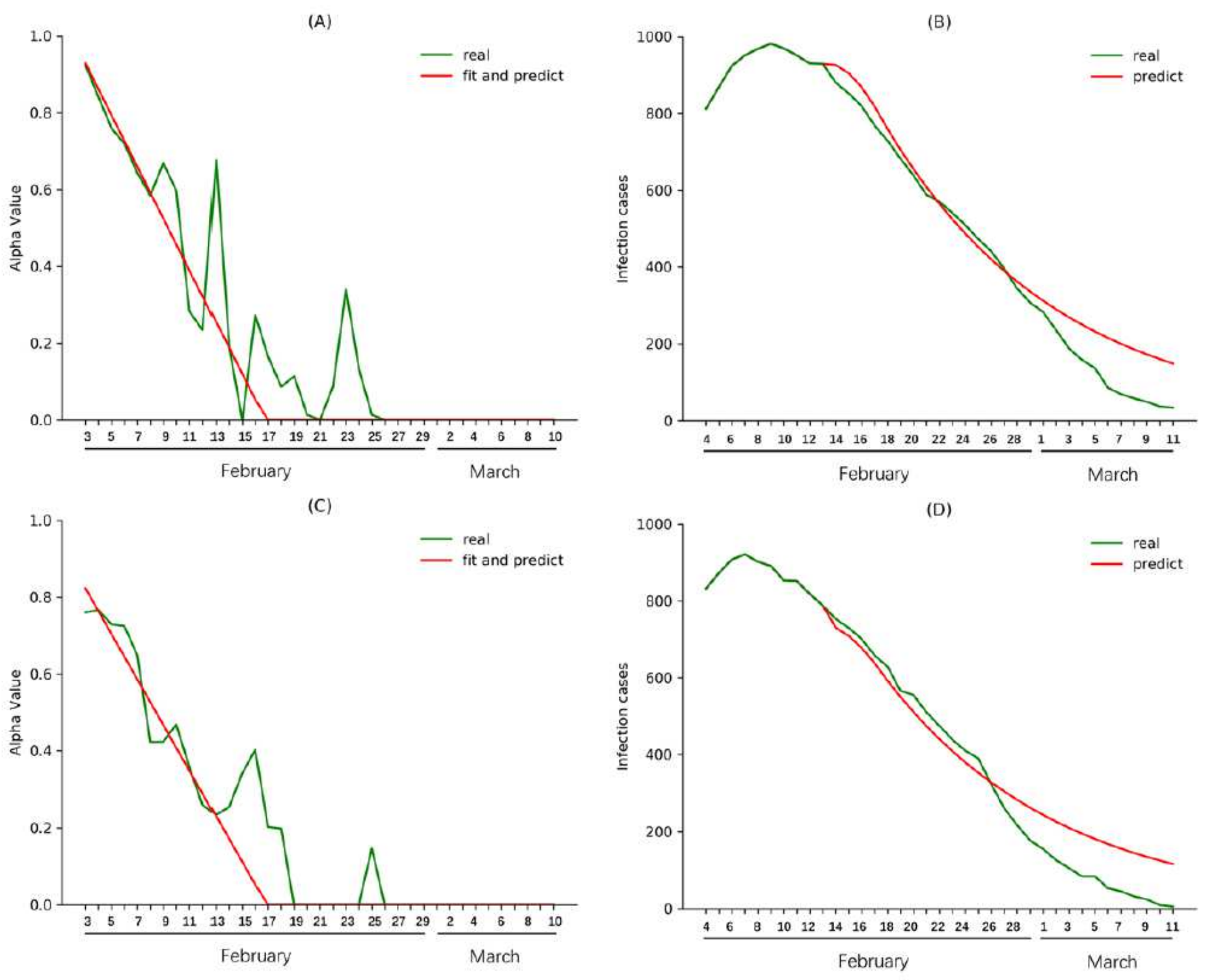

\section{Figure 1}

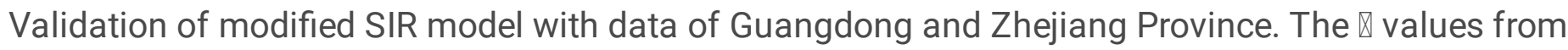
February 3rd to February 12th (before nationwide intensive community screening but after Wuhan city lockdown) were used to predict $\otimes$ values from February 13th to March 10th for Guangdong (A) and

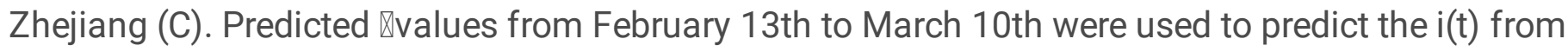
February 14th to March 11th for Guangdong (B) and Zhejiang (D). 
(A)

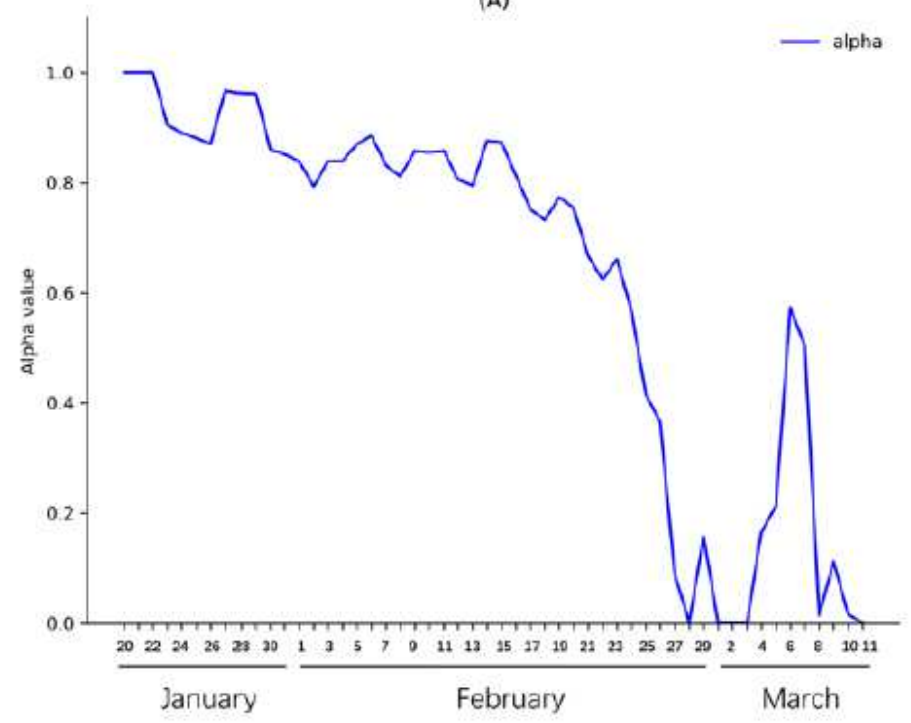

(C)

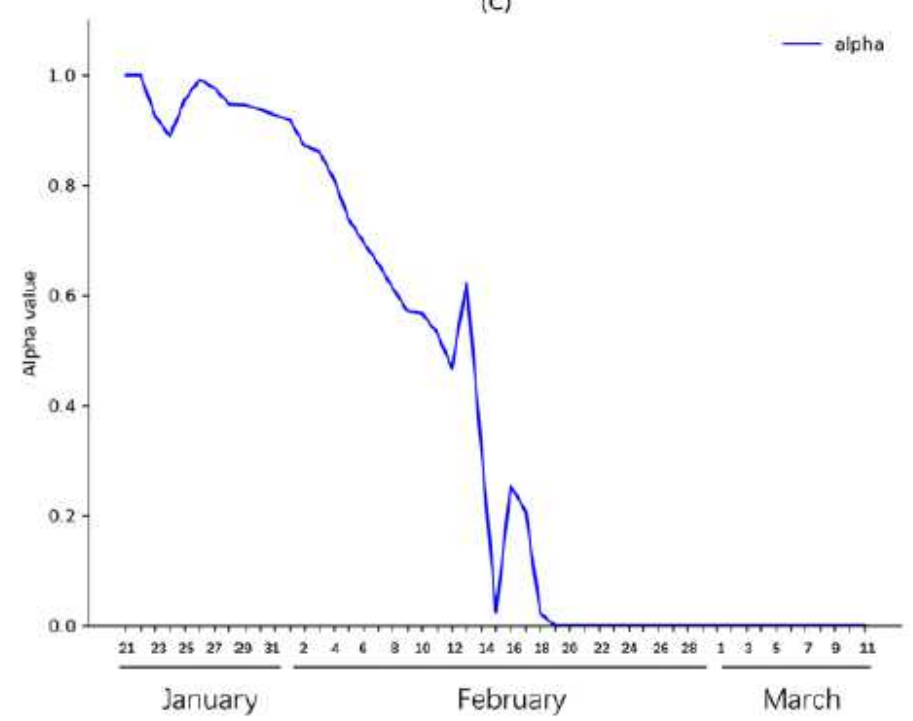

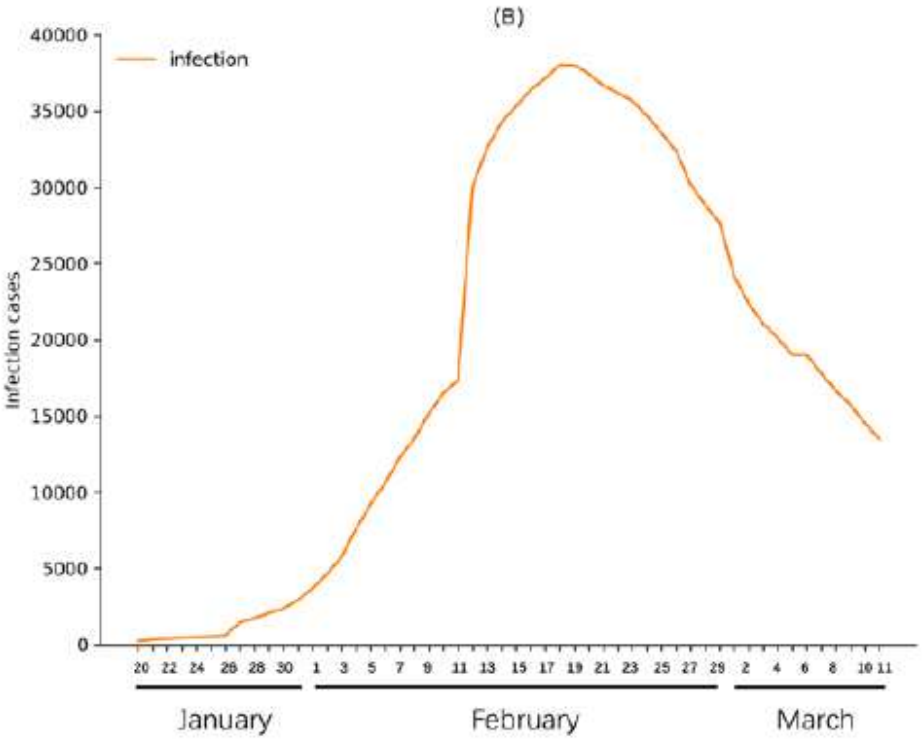

(D)

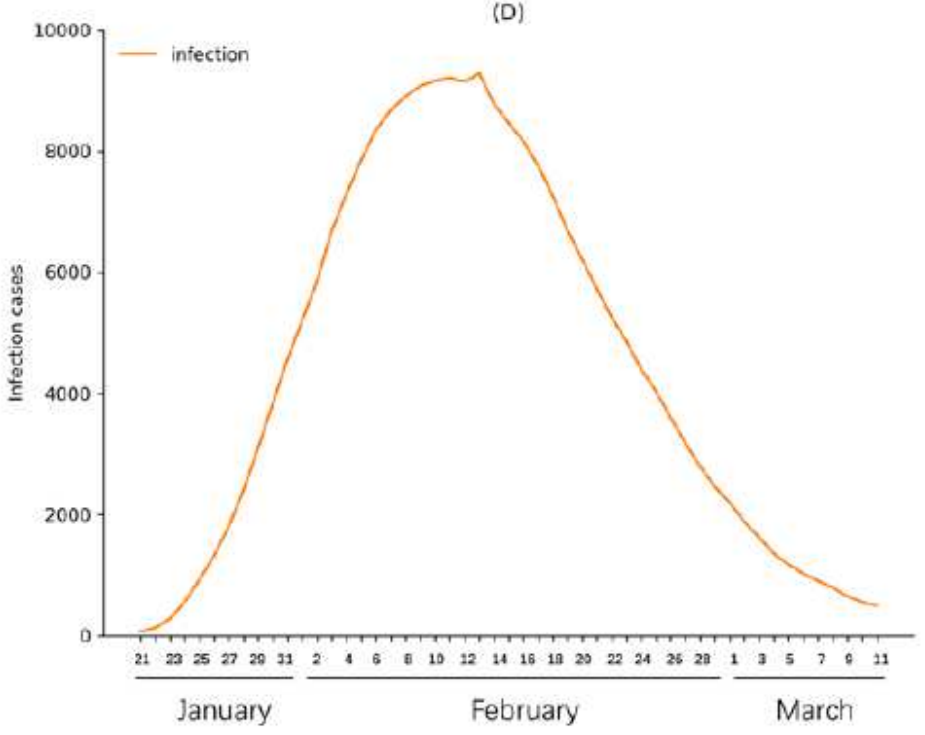

Figure 2

Real world $\otimes$ value and infection cases of Wuhan city from January 20th to March 11th and China excluding Hubei from January 21th to March 11th. Real Qषvalue (A) and infection cases (B) of Wuhan city; Real $\otimes$ value (C) and infection cases (D) of China excluding Hubei. 

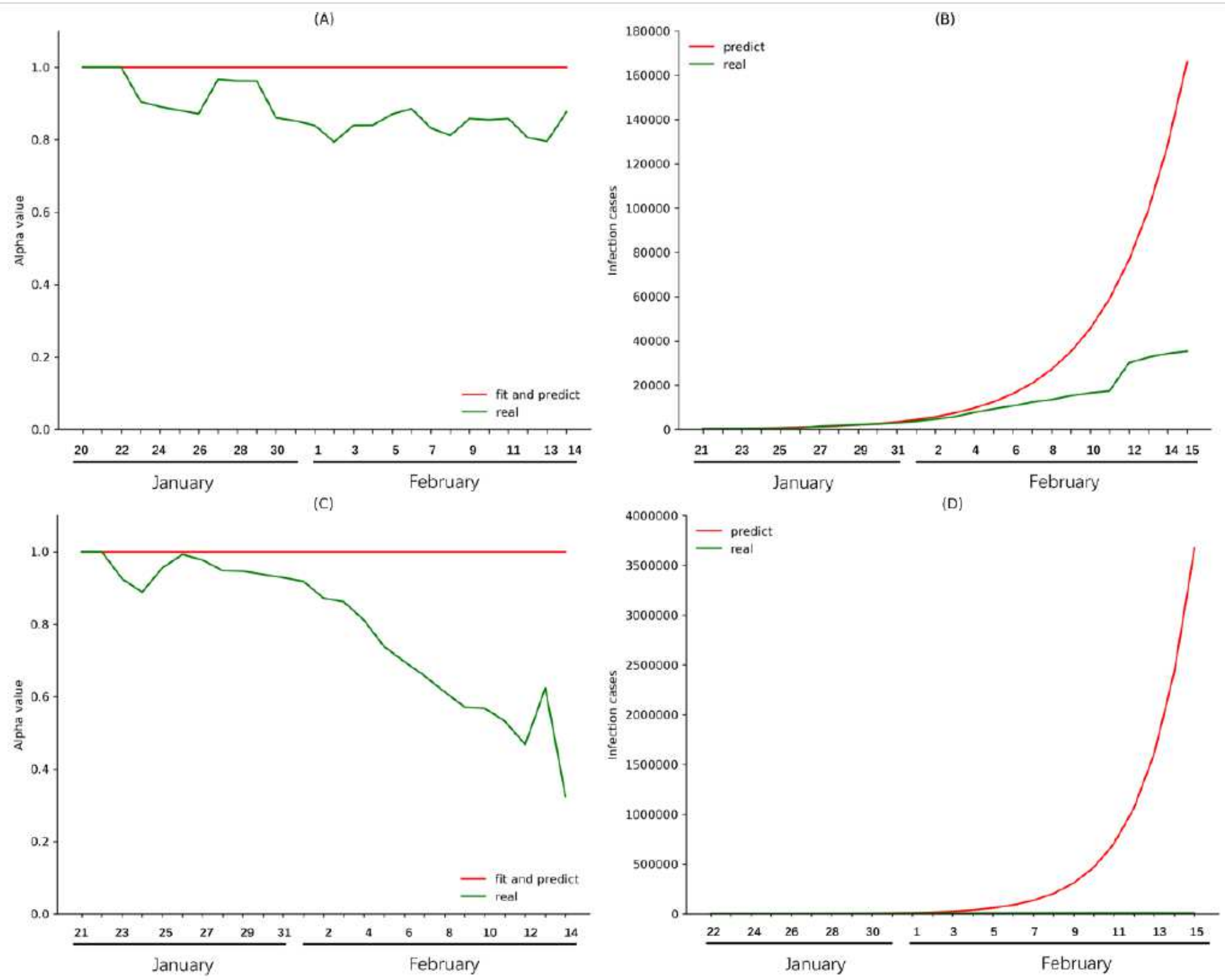

\section{Figure 3}

Impact of city lockdown on Wuhan city and China excluding Hubei province. (A) $\nabla$ values of Wuhan city from January 20th to January 22th (before city lockdown) were used to predict the $\mathbb{Q}$ value from January 23th to February 14th without city lockdown. (B) Predicted $\nabla$ values were used to calculate the infection number of Wuhan city from January 24th to February 15th. (C) $₫$ values of China excluding Hubei province from January 21th to January 22th were used to predict the $₫$ value from January 23th to February 14th without city lockdown. (D) Predicted $\nabla$ values were used to calculate the infection cases of China excluding Hubei province from January 24th to February 15th. 

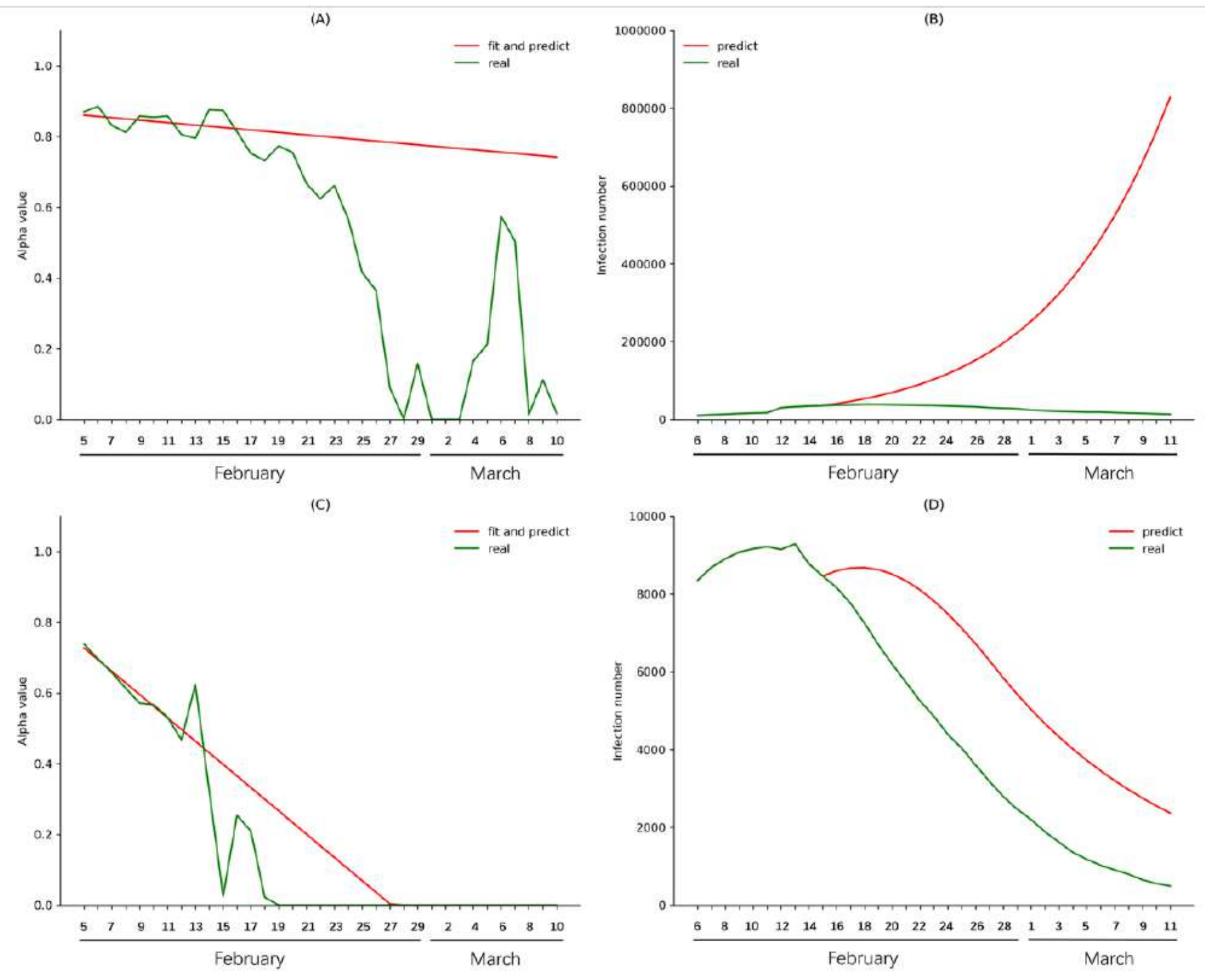

\section{Figure 4}

Impact of intensive community screening on Wuhan city and China excluding Hubei province $\triangle A \otimes \square$ value

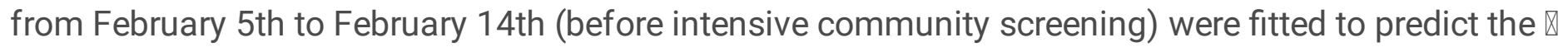
value of Wuhan city from February 15th to March 10th without intensive community screening. (B) predicted $\square$ values were used to calculate the infection cases of Wuhan city from February 16th to March 11th. (C) $\otimes$ value of China excluding Hubei Province from February 5th to February 14th were used to predict the $\otimes$ value of China excluding Hubei Province from February 15th to March 10th without intensive community screening. (D) predicted $\otimes$ values were used to calculate the infection number of China excluding Hubei Province from February 16th to March 11th. 

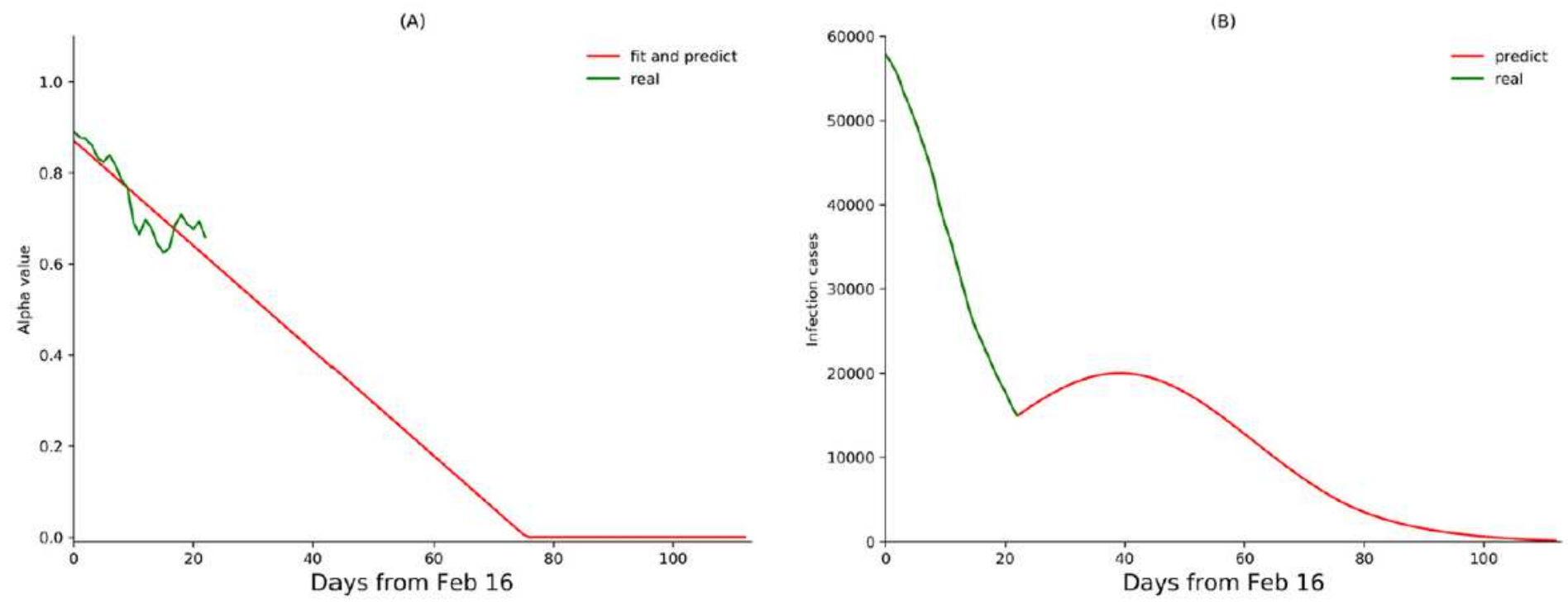

Figure 5

Prediction of the epidemic trend in China $(A) \otimes$ values from February 16th to March 10th were fitted to predict $\nabla$ values of 90 days from March 11th. (B) predicted $\nabla$ values were used to predict future infection

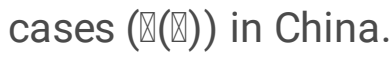



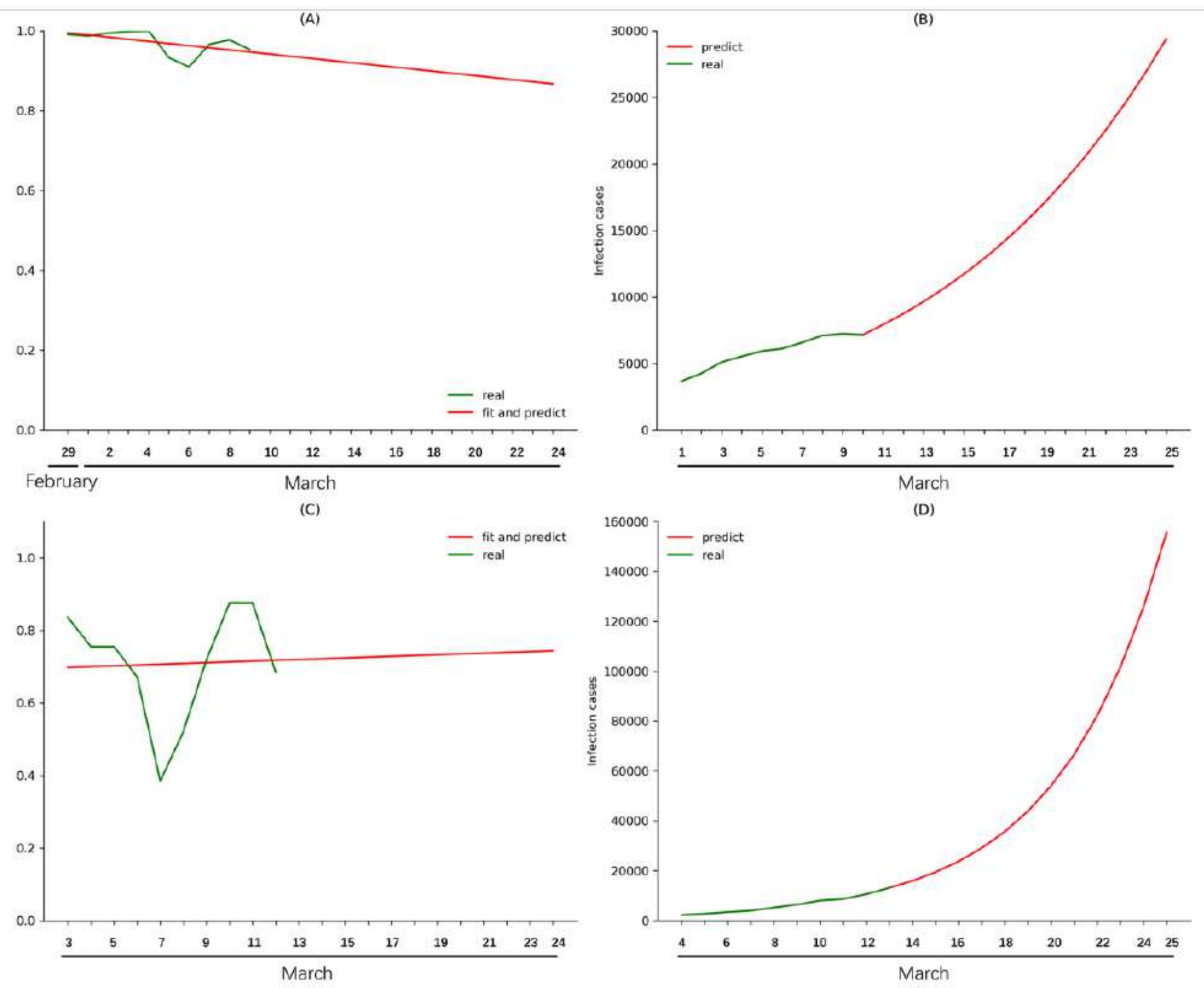

Figure 6

Prediction of the epidemic trend in South Korea and Italy. (A) $₫$ values from February 29th to March 9th were fitted to predict $\nabla$ values from March 10th to March 24th (B) predicted $\otimes$ values were used to calculate the infection cases from March 14th to March 25th. (C) $₫$ values from March 3th to March 12th were fitted to predict $\otimes$ values from March 13th to March 24th. (B) The predicted infection cases from March 14th to March 25th. 